\title{
Administration and burden of subcutaneous immunotherapy for allergic rhinitis in clinical practice in Canada
}

\author{
Steven W Blume ${ }^{1}$, Karen Yeomans ${ }^{2}$, Harold Kim', Sunning Tao ${ }^{2}$, Stephanie M Hubbard ${ }^{3}$, Felicia Allen-Ramey ${ }^{4^{*}}$ \\ From Canadian Society of Allergy and Clinical Immunology Annual Scientific Meeting 2013 \\ Toronto, Canada. 3-6 October 2013
}

\section{Background}

Allergic rhinitis (AR) has been estimated to affect approximately 20-25\% of Canadians. [1] Management of AR encompasses allergen avoidance, use of symptomatic medications, and allergen immunotherapy for patients unresponsive to other pharmacotherapy. [2,3] This study was conducted to characterize patients receiving subcutaneous immunotherapy (SCIT) and the SCIT administration process in Canada and the United States; Canadian results are presented.

\section{Methods}

A multi-center, prospective, observational study was conducted at 5 allergy clinics in Quebec and Ontario and 1 primary care clinic in Quebec from March-September 2012. Patients $\geq 6$ years who were scheduled for SCIT on study days were invited to participate in the study. Patients enrolled in a clinical trial, receiving sublingual immunotherapy or allergic only to insect venom, latex, food, or drugs were excluded. Site and patient-specific information were captured via direct observation, questionnaires, and medical chart review. Costs were estimated from time and supply observation and query.

\section{Results}

A total of 294 patients were enrolled with a mean age of 44 years $(4 \%<18$ years and $9 \% \geq 65$ years). Of these, $59 \%$ were female, $81 \%$ Caucasian, $57 \%$ employed full-time and $30 \%$ reported household income $\geq \$ 100,000$. Concomitant allergy medications were reported by $66 \%$ of patients; $25 \%$ used asthma medications. Two-thirds of patients reported initiating SCIT because they desired a cure

\footnotetext{
* Correspondence: felicia.ramey@merck.com

${ }^{4}$ Merck \& Co., Inc., West Point, PA, 19486, USA

Full list of author information is available at the end of the article
}

"once and for all" for their allergies. Primary symptoms at initiation of SCIT were nasal congestion (62\%), rhinorrhea (59\%), sneezing (35\%) and itchy eyes (32\%). Chart data indicated that patients received treatment for several different antigens (mean: 4; SD: 3 ); those most commonly noted were ragweed $(82 \%)$, house dust mites $(55 \%)$, grass $(48 \%)$ and tree (48\%). Sites reported a SCIT build-up phase requiring one injection/week over 12-52 weeks. The SCIT maintenance phase was reported as one injection/month over 4-5 years. Site-specific means (SDs) for total patient time in the clinic for SCIT ranged from 32 (11) to 49 (10) minutes, including a 30-minute required post-injection observation at all but one site. Average patient travel time to the office for SCIT was 20 (SD: 14) minutes. Mean time missed from work in the previous week was 0.7 hours. The direct costs of an injection ranged from $\$ 14$ to $\$ 41$ by site, with extract preparation or acquisition and administrative tasks the largest components.

\section{Conclusions}

Patients initiated SCIT to permanently resolve allergy symptoms. SCIT requires a long-term commitment, resulting in considerable direct and indirect costs.

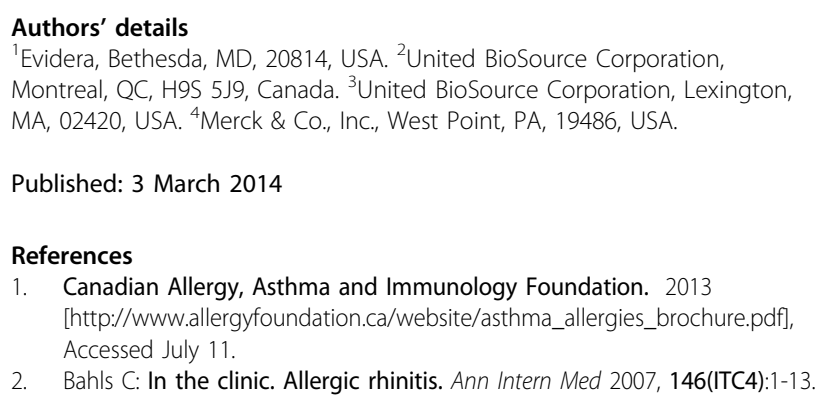


3. Price D, Bond C, Bouchard J, et al: International Primary Care Respiratory Group (IPCRG) Guidelines: management of allergic rhinitis. PrimCare Respir J 2006, 15:58-70.

doi:10.1186/1710-1492-10-S1-A10

Cite this article as: Blume et al:: Administration and burden of

subcutaneous immunotherapy for allergic rhinitis in clinical practice in Canada. Allergy, Asthma \& Clinical Immunology 2014 10(Suppl 1):A10.

Submit your next manuscript to BioMed Central and take full advantage of:

- Convenient online submission

- Thorough peer review

- No space constraints or color figure charges

- Immediate publication on acceptance

- Inclusion in PubMed, CAS, Scopus and Google Scholar

- Research which is freely available for redistribution

Submit your manuscript at www.biomedcentral.com/submit
C Biomed Central 